Bull. Mater. Sci., Vol. 5, No.2, June 1983, pp. 133-137. (C) Printed in India.

\title{
Dielectric and pyroelectric properties of sintered discs of sodium meta vanadate
}

\author{
A H KHAN, D B GHARE* and P S NARAYANAN** \\ Department of Physics, Jahangirnagar University, Savar, Dacca, Bangladesh \\ * Department of High Voltage Engineering, \\ ** Department of Physics, Indian Institute of Science, Bangalore 560 012, India \\ MS received 2 July 1982; revised 16 August 1982
}

\begin{abstract}
The dielectric and pyroelectric properties of poled and unpoled sintered discs of sodium meta vanadate were investigated in the temperature range from room temperature to $450^{\circ} \mathrm{C}$. Dielectric constant and loss tangent anomalies were found around $375-390^{\circ} \mathrm{C}$, while in pyroelectric coefficient, two anomalies were noticed at $250 \pm 25^{\circ} \mathrm{C}$ and $360 \pm 50^{\circ} \mathrm{C}$ respectively.
\end{abstract}

Keywords. Ferroelectricity; pyroelectric behaviour; phase transition; sodium meta vanadate; sintered dielectric materials.

\section{Introduction}

Sawada and Nomura (1951) reported that $\mathrm{NaVO}_{3}$ is ferroelectric below $380^{\circ} \mathrm{C}$. Matsuda (1974) studied the dielectric dispersion in $\mathrm{NaVO}_{3}$ single crystals grown by Czochralski technique. Shaikh et al (1978) and Ramani et al (1975) described the structural features of $\mathrm{NaVO}_{3}$ single crystals and the variations in lattice parameters in the temperature range from room temperature to $500^{\circ} \mathrm{C}$. The growth of $\mathrm{NaVO}_{3}$ and a detailed laser Raman and infrared study were undertaken to find out the exact structural features at room temperature and the origin of ferroelectricity in $\mathrm{NaVO}_{3}$. Sintered ceramic discs of $\mathrm{NaVO}_{3}$ were prepared to study its pyroelectric behaviour and $\varepsilon_{r}$ and it was found that the ceramic discs showed an unusually large $\varepsilon_{r}$ near the transition temperature.

\section{Experimental procedure}

Polycrystalline sodium metavanadate powder $(10-50 \mu \mathrm{m})$ (LR 99.8\%) was pressed in the form of discs (18 mm diam; thickness $0.5-2 \mathrm{~mm}$ ) at a pressure of $300 \mathrm{~kg} / \mathrm{cm}^{2}$. The discs were sintered in a platinum crucible at $520^{\circ} \mathrm{C}$ for $3 \mathrm{hr}$ and then allowed to cool to room temperature inside the furnace after it was switched off. The samples were polished and three different types of electrodes used for making electrical contacts (on different samples), with air-drying silver paste and vacuumevaporated aluminium and chromium films. 
The capacitance and tan $\delta$ vs temperature were measured in the temperature range from room temperature to $450^{\circ} \mathrm{C}$ using Marconi Universal Bridge No. TF 1313 at 1 and $10 \mathrm{kHz}$. Pyroelectricity was measured in the same temperature range by uniformly heating the sample at $1.2^{\circ} \mathrm{C}$ per min using the Keithley digital microvoltmeter (model No. 177) and the pyroelectric coefficients were calculated using equations given by Lang et al (1965a). Poling of the samples was carried out at $220^{\circ} \mathrm{C}$ for $15 \mathrm{~min}$ at a field strength of $3 \mathrm{kV} / \mathrm{cm}$. The dielectric constant $\varepsilon_{r}$, tan $\delta$, and pyroelectric coefficient $v$ s temperature measurements were repeated on poled samples, in the same temperature range, to determine the effect of such poling operation on these properties of the material.

\section{Results and discussion}

The graphs of dielectric loss ( $\tan \delta$ ) as a function of temperature measured at 1 and $10 \mathrm{kHz}$ given in the inset of figure 1 show that the loss tangent at $1 \mathrm{kHz}$ increased beyond the compensation range provided in the bridge at temperatures above $200^{\circ} \mathrm{C}$. Further measurements of $\varepsilon_{r}$ upto $450^{\circ} \mathrm{C}$ were therefore carried out at $10 \mathrm{kHz}$ only.

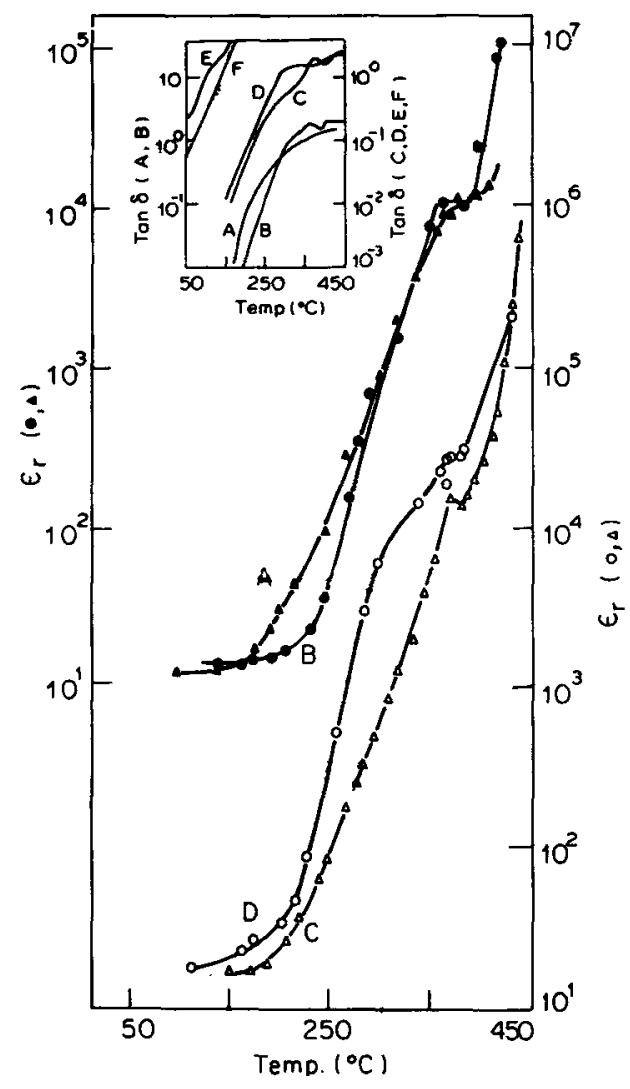

Figure 1. Variations in relative permittivity as a function of temperature for sintered discs of $\mathrm{NaVO}_{3}$. A,B. Aluminium electrode, before and after poling respectively at $10 \mathrm{kHz}$. C,D. Chromium electrode before and after poling respectively at $10 \mathrm{kHz}$. (Inset) Variations in tan $\delta$ as a function of temperature. $\mathbf{A}, \mathbf{B}, \mathbf{C}$ and $\mathbf{D}$ as above. $\mathbf{E , F}$. Silver electrode before and after poling respectively at $1 \mathrm{kHz}$. 
The maxima in tan $\delta$ at $10 \mathrm{kHz}$ shift to a higher temperature which is in agreement with the results reported by Matsuda (1974) on $\mathrm{NaVO}_{3}$ single crystals. The dielectric constant of the sintered disc samples (at $10 \mathrm{kHz}$ ) (figure 1) increased sharply above $200^{\circ} \mathrm{C}$, exhibited a small dip at around $380^{\circ} \mathrm{C}$ and continued to increase further. Similar behaviour was noticed at corresponding temperatures in the graphs of tan $\delta$ vs temperature (at $10 \mathrm{kHz}$ ). It can also be seen that the dip in $\varepsilon_{r}$ around $380-390^{\circ} \mathrm{C}$ is independent of electrode material and poling. After poling the rate of increase in $\varepsilon_{r}$ as a function of temperature, in the temperature range $200-350^{\circ} \mathrm{C}$ is much sharper and a linear relationship exists between $\log \varepsilon_{r}$ and temperature. For poled samples the relationship between $\log (\tan \delta)$ vs temperature is also almost linear in the temperature range between 200 and $300^{\circ} \mathrm{C}$.

One finds that the relative permittivity increases exponentially at temperatures above $400^{\circ} \mathrm{C}$ which is unexpected if a ferroelectric-paraelectric transition has taken place at $380-390^{\circ} \mathrm{C}$. The differential thermal analysis (DTA) and differential scanning calorimetric (DSC) studies on sodium meta vanadate powders in the temperature range from room temperature to $500^{\circ} \mathrm{C}$ also did not reveal any signs of a first order transition around $380^{\circ} \mathrm{C} \pm 20^{\circ} \mathrm{C}$. Thus this dielectric behaviour may be explained on the basis of slight nonstoichiometric conditions created at high temperatures by the loss of oxygen (similar to the behaviour reported on vanadium bronzes by Pletneva et al 1979; Volkov et al 1976).

The plots of pyroelectric coefficient as a function of temperature are shown in figure 2. Samples with silver paste electrodes initially exhibited several anomalous peaks and dips in the first run only (not shown in figure 2). In subsequent repetitions of these measurements only two peaks are however observed corresponding to temperatures around 240 and $340^{\circ} \mathrm{C}$ respectively. The other peaks exhibited by all samples at the same corresponding temperatures in their first run of measurements were identified due to the effect of this kind, depending on electrode

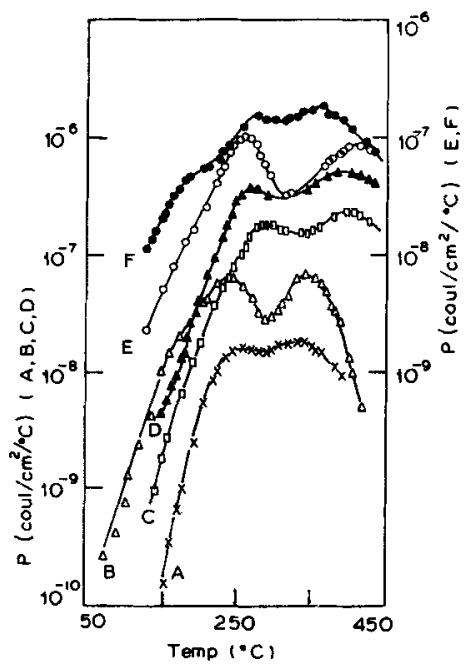

Figure 2. Variations in pyroelectric coefficient as a function of temperature for sintered discs of $\mathrm{NaVO}_{3}$. A,B. Silver electrode before and after poling respectively. C,D. Aluminium electrode before and after poling respectively. E,F. Chromium electrode before and after poling resfectively. 
Table 1. Data on position of peaks in the pyroelectric coefficient exhibited by $\mathrm{NaVO}_{3}$ sintered discs.

\begin{tabular}{|c|c|c|c|c|}
\hline \multirow{2}{*}{$\begin{array}{l}\text { Electrode } \\
\text { material }\end{array}$} & \multicolumn{2}{|c|}{$\begin{array}{l}\text { Position of peak No. } 1 \\
\text { w.r.t. temperature }\left({ }^{\circ} \mathrm{C}\right)\end{array}$} & \multicolumn{2}{|c|}{$\begin{array}{l}\text { Position of peak No. } 2 \\
\text { w.r.t. temperature }\left({ }^{\circ} \mathrm{C}\right)\end{array}$} \\
\hline & $\begin{array}{l}\text { Unpoled } \\
\text { sample }\end{array}$ & $\begin{array}{l}\text { Poled } \\
\text { sample }\end{array}$ & $\begin{array}{l}\text { Unpoled } \\
\text { sample }\end{array}$ & $\begin{array}{l}\text { Poled } \\
\text { sample }\end{array}$ \\
\hline Silver paste & 255 & 240 & 330 & 340 \\
\hline $\begin{array}{l}\text { Aluminium } \\
\text { (vacuum evaporated) }\end{array}$ & 280 & 275 & 400 & 390 \\
\hline $\begin{array}{l}\text { Chromium } \\
\text { (vacuum evaporated) }\end{array}$ & 260 & 275 & 420 & 380 \\
\hline
\end{tabular}

material during its first firing operations. This was also confirmed by the fact that the samples with aluminium and chromium vacuum evaporated electrodes did not exhibit these additional peaks and dips even in their first run of measurements.

The plots of pyroelectric coefficient as a function of temperature shown in figure 2 are the stabilised values obtained in subsequent runs. The pyroelectric coefficient exhibited by samples with aluminium and chromium vacuum evaporated electrodes also shows two peaks at temperatures as summarised in table 1 .

It can be seen from table 1 that the position of these two peaks (with respect to temperature) were slightly altered as a result of change in the electrode material. The poling did not lead to any substantial change in the position of the peaks, eventhough it resulted in increase of the magnitude of the pyroelectric coefficient by almost one order of magnitude in all types of samples. It is therefore definite that $\mathrm{NaVO}_{3}$ belongs to the polar class at room temperature and above $380^{\circ} \mathrm{C}$ it is nonpolar.

\section{Conclusions}

The dielectric constant $v$ s temperature characteristics of sintered discs of $\mathrm{NaVO}_{3}$ exhibited steeply rising values of $\varepsilon_{y}$ in the temperature range 200 to $450^{\circ} \mathrm{C}$. In view of the very high ohmic values of the samples at high temperatures and high field strengths, this phenomenon seems to be intrinsic in nature and cannot be attributed only to grain boundary effects. The DTA and DSC data did not show any evidence of a first order transition at $380^{\circ} \mathrm{C}$. The pyroelectric coefficient variation with temperature has been used to establish that $\mathrm{NaVO}_{3}$ belongs to the polar class at room temperature and that its high temperature phase is non-polar.

\section{Acknowledgements}

The authors wish to thank Prof. R Srinivasan, and Prof. V Prabhashankar, (Indian Institute of Science) for their assistance. Thanks are due to $\mathrm{Mr}$ Seetharam for placing 
at their disposal some of his thermal and optical results under publication. One of the authors (AHK) also wishes to thank the authorities of the Jahangirnagar University and UGC.

\section{References}

Lang S B and Steal F 1965a Rev. Sci. Instrum. 36929

Lang S B and Steal F 1965b Rev. Sci. Instrum. 361817

Matsuda M 1974 J. Phys. Soc. Jpn. 36759

Pletneva E D, Khodos M Ya, Volkov V L and Fotiev A A 1979 Inorganic materials (USA) 15670

Ramani K, Shaikh A M, Reddy B S and Viswamitra M A 1975 Ferroelectrics 949

Sawada S and Nomura S $1951 \mathrm{~J}$. Phys. Soc. Jpn. 6192

Stiaikh A M, Viswamitra M A and Narayanan P S 1978 Ferroelectrics 20311

Volkov V L, Kapustkin V K, Fotiev A A and Miroshnikova L D 1976 Inorganic Materials(USA) 121795 